\title{
Posterior Reversible Encephalopathy Syndrome (PRES) in Rheumatic Autoimmune Disease
}

\author{
Izzat Khanjar, Ibrahim Abdulmomen, Yousef M. Yahia,_Abdul-Wahab Al-Allaf, \\ Rheumatology Department, Hamad Medical Corporation, Doha, Qatar
}

How to cite this article: Khanjar I, Abdulmomen I, Yahia YM, Al-Allaf AW. Posterior reversible encephalopathy syndrome (PRES) in rheumatic autoimmune disease. EJCRIM 2018;5: doi:10.12890/2018_000866.

Conflicts of Interests: The Authors declare that there are no competing interests.

This article is licensed under a Commons Attribution Non-Commercial 4.0 License

\section{ABSTRACT}

Posterior reversible encephalopathy syndrome (PRES) is a clinical-radiological entity with many causes. The primary abnormality is cerebral vasogenic oedema. Here we describe the management of five patients with PRES syndrome who presented to our hospital.

\section{LEARNING POINTS}

- Posterior reversible encephalopathy syndrome (PRES) presents with cerebral vasogenic oedema.

- PRES resolves when blood pressure is controlled.

- Patients with a history of autoimmune disorder who present with confusion may have PRES.

\section{KEYWORDS}

PRES, posterior reversible encephalopathy syndrome, rheumatic autoimmune disease

\section{INTRODUCTION}

Posterior reversible encephalopathy syndrome (PRES) is a clinical-radiological entity that was well described by Hinchey in $1996^{[1]}$. It has different names, but PRES is now the accepted term ${ }^{[2,3]}$. PRES has many causes, but the primary abnormality is cerebral vasogenic oedema ${ }^{[1,2]}$. Here we describe the management of five patients with PRES who presented to our hospital (Table 1).

\section{CASE PRESENTATIONS}

Case 1: PRES after immunosuppression in a patient with systemic lupus erythematosus

A 34-year-old woman with systemic lupus erythematosus (SLE) and lupus nephritis class IV was started on cyclophosphamide and rituximab in addition to IV methylprednisolone. After the second dose of cyclophosphamide, she developed generalized tonic-clonic seizures associated with headache and decreased vision, with high blood pressure of 190/100 mmHg. MRI findings showed a multifocal, irregular patchy area of high signal intensity in the parietal-occipital cortical and subcortical areas bilaterally, which was consistent with PRES (Fig. 1). The blood pressure and seizures were successfully managed, and the patient was discharged home after 6 days. 
Case 2: PRES after immunosuppression in a patient with SLE

A 23-year-old woman was diagnosed with lupus nephritis and refractory autoimmune haemolytic anaemia. Two weeks after initiation of cyclophosphamide and rituximab therapy in addition to IV methylprednisolone, she presented to the emergency department with toniccolonic convulsions, high blood pressure and worsening kidney function. The patient required intubation. MRI of the brain showed lesions typical of PRES, as in Case 1. The patient improved dramatically after the high blood pressure and seizures were brought under control.

Case 3: PRES after immunosuppression in another patient with SLE

A 41-year-old woman with lupus nephritis presented to the emergency department with a history of convulsions and high blood pressure 2 weeks after receiving pulse methylprednisolone followed by mycophenolate for the lupus nephritis. The patient required intubation and haemodialysis. MRI of the brain showed lesions typical of PRES, as in Case 1 . She was treated with antihypertensive medications and antiepileptics with complete resolution of her symptoms. She was extubated after 2 days and discharged home after 16 days.

\section{Case 4: PRES after pulse methylprednisolone therapy in a patient with SLE}

A 29-year-old woman with known SLE on conventional treatment including hydroxychloroquine and azathioprine, presented to the emergency department with fever, headache and pancytopenia. Investigations showed she had Epstein-Barr virus (EBV). Antibiotics and pulse steroids were administered for her SLE flare. However, she experienced seizures 3 days later. MRI of the brain indicated PRES, and the patient was transferred to the ICU. She developed diffuse alveolar haemorrhage (DAH) and later haemophagocytic lymphocytosis (HLH) which made treatment more difficult. The patient recovered but required extensive rehabilitation.

\section{Case 5: PRES in a postpartum woman}

A 41-year-old woman was transferred to the emergency from another hospital because of postpartum haemorrhage after a normal vaginal delivery. She presented with sudden impaired vision and left-sided weakness associated with high blood pressure. She was referred to rheumatology services for possible vasculitis, but vasculitis and other connective tissue diseases were excluded. MRI of the brain revealed a typical picture of PRES, as in Case 1. The patient responded well after her blood pressure was controlled, and all symptoms resolved.

\section{DISCUSSION}

PRES is a life-threatening condition which is characterized by symmetrical involvement of posterior white matter. It usually presents with neurological impairments such as seizure, altered mental status, headache and visual disturbance ${ }^{[2]}$ with typical MRI findings of hyperintense lesions on FLAIR images in the parietal-occipital and posterior frontal cortical and subcortical white matter. Less commonly, the brainstem, basal ganglia and cerebellum are involved. Atypical imaging showing contrast enhancement, haemorrhage and restricted diffusion on 
MRI has also been reported ${ }^{[4]}$. The epidemiology of PRES is unknown but the condition normally occurs in young to middle-aged adults with a marked female predominance ${ }^{[5]}$. The pathophysiology of PRES remains elusive. However, it has been suggested that compromised cerebrovascular autoregulation due to acute hypertension may play a pivotal role. Accordingly, impaired cerebrovascular regulation may lead to arteriole leakage and cerebral vasogenic oedema ${ }^{[2]}$. The extensive use of immunosuppressive therapy (methylprednisolone, dexamethasone, cyclosporine and cyclophosphamide) ${ }^{[2]}$ and the autoimmune nature of rheumatological diseases including SLE may render patients more vulnerable to developing PRES over the course of the disease ${ }^{[6]}$.

We describe five cases of PRES, four of which had a background of SLE, with the other case being postpartum. Four of our five patients required mechanical ventilation, which is higher than reported in the literature, where ventilation was needed in $35 \%-40 \%$ of patients with PRES ${ }^{[7]}$.

All four SLE patients were female and developed PRES after the initiation of immunosuppression therapy, mainly pulsed methylprednisolone; Cases 1 and 2 had also received a combination of cyclophosphamide and rituximab. The most common presentation of PRES is seizure (74\%-92\% of patients), followed by encephalopathy (28\%-92\%), headaches (26\%-83\%) and visual disturbances (20\%-63\%) ${ }^{[8]}$, as also seen in our series, where four of the five patients presented with seizure. All our patients also reported headache and impaired vision, which is much higher than normally reported. Case 5 developed left-sided weakness as well. The most common associated sign is high blood pressure (53\%-91.7\%) $)^{[9]}$, which was seen in all our patients. The main management of PRES consists of blood pressure control, treatment of associated seizures and removal of the causative agent ${ }^{[10]}$.

It is uncommon for patients to develop recurrent PRES ${ }^{[11,12]}$ and very rare for it to occur more than twice, but two of our five patients had recurrent PRES, which might have been due non-compliance with medications together with the progressive nature of the lupus in some patients.

\begin{tabular}{|c|c|c|c|c|c|}
\hline & Case 1 & Case 2 & Case 3 & Case 4 & Case 5 \\
\hline Age, years & 34 & 23 & 41 & 29 & 41 \\
\hline Sex & Female & Female & Female & Female & Female \\
\hline Main presentation & $\begin{array}{l}\text { Headache impaired } \\
\text { vision } \\
\text { Convulsion and high } \\
\text { blood pressure }\end{array}$ & $\begin{array}{l}\text { Headache, vomiting, } \\
\text { convulsions and } \\
\text { high blood pressure }\end{array}$ & $\begin{array}{l}\text { Headache } \\
\text { Convulsions and } \\
\text { high blood pressure }\end{array}$ & Seizures & $\begin{array}{l}\text { Headache impaired } \\
\text { vision } \\
\text { High blood pressure } \\
\text { Left-sided weakness }\end{array}$ \\
\hline Medical illness & Lupus nephritis & $\begin{array}{l}\text { Lupus nephritis and } \\
\text { autoimmune haemolytic } \\
\text { anaemia }\end{array}$ & Lupus nephritis & $\begin{array}{l}\text { Systemic lupus } \\
\text { erythematosus }\end{array}$ & $\begin{array}{l}\text { Postpartum vaginal } \\
\text { bleeding }\end{array}$ \\
\hline Previous medication & $\begin{array}{l}\text { Cyclophosphamide } \\
\text { and rituximab with pulse } \\
\text { methylprednisolone }\end{array}$ & $\begin{array}{l}\text { Cyclophosphamide and } \\
\text { rituximab with pulse } \\
\text { methylprednisolone }\end{array}$ & $\begin{array}{l}\text { Pulse } \\
\text { methylprednisolone }\end{array}$ & $\begin{array}{l}\text { Pulse } \\
\text { methylprednisolone }\end{array}$ & None \\
\hline $\begin{array}{l}\text { Required ICU } \\
\text { management and } \\
\text { mechanical ventilation }\end{array}$ & Yes & Yes & Yes & Yes & No \\
\hline $\begin{array}{l}\text { Duration of hospital } \\
\text { stay }\end{array}$ & 6 Days & 16 Days & 15 Days & 20 Days & 6 Days \\
\hline $\begin{array}{l}\text { Previous history of } \\
\text { PRES }\end{array}$ & Yes (3 times) & No & No & Yes (3 times) & No \\
\hline
\end{tabular}




\section{CONCLUSION}

The differential diagnosis of a patient who presents with altered mental status, headache or seizure should include PRES, especially if they have a rheumatological disease treated with immunosuppression. This is a significant point as symptoms of PRES can mimic flare or active disease in a patient with a rheumatological illness, but the management is entirely different.

\section{REFERENCES}

1. Hinchey J, Chaves C, Appignani B, et al. A reversible posterior leukoencephalopathy syndrome. N Engl J Med 1996;334:494-500

2. Bartynski WS. Posterior reversible encephalopathy syndrome, part 2: controversies surrounding pathophysiology of vasogenic oedema. AJNR Am J Neuroradiol 2008;29:10431049

3. Casey SO, Sampaio RC, Michel E, et al. Posterior reversible encephalopathy syndrome: utility of fluid-attenuated inversion recovery MR imaging in the detection of cortical and subcortical lesions. AJNR Am J Neuroradiol 2000;21:1199-1206.

4. McKinney AM, Short J, Truwit CL et al. Posterior reversible encephalopathy syndrome: incidence of atypical regions of involvement and imaging findings. Am J Roentgenol 2007:189:904-912

5. Vincent JL (ed). Annual update in intensive care and emergency medicine 2011. New York: Springer, 813 pp.

6. Rahmanzadeh R, Rahmanzade R, Zabihiyeganeh M. Posterior reversible encephalopathy syndrome in a patient with mixed connective tissue disease: a case report. J Med Case Rep 2016;10:145.

7. Burnett MM, Hess CP, Roberts JP, et al. Presentation of reversible posterior leukoencephalopathy syndrome in patients on calcineurin inhibitors. Clin Neurol Neurosurg 2010;112:886-889.

8. Fugate JE, Claassen DO, Cloft HJ, et al. Posterior reversible encephalopathy syndrome: associated clinical and radiologic findings. Mayo Clin Proc 2010;85:427-432.

9. Schwartz RB, Jones KM, Kalina P, et al. Hypertensive encephalopathy: findings on CT, MR imaging, and SPECT imaging in 14 cases. AJR Am J Roentgenol 1992;159:379-383.

10. Striano P, Striano S, Tortora F, et al. Clinical spectrum and critical care management of posterior reversible encephalopathy syndrome (PRES). Med Sci Monit 2005;11:CR54953.

11. Abe T, Tokuda Y. Recurrent posterior reversible encephalopathy syndrome of the brainstem in a hypertensive patient with end-stage renal disease. J Emerg Trauma Shock 2014;7:242-243.

12. Roy S, Gandhi AK, Jana M, Julka PK. Recurrent posterior reversible encephalopathy syndrome after chemotherapy in hematologic malignancy-posterior reversible encephalopathy syndrome can strike twice!!! J Cancer Res Ther 2014;10:393-396. 